\title{
Association of endogenous testosterone with blood pressure and left ventricular mass in men. The Tromso Study
}

\author{
Johan Svartberg, Denise von Mühlen ${ }^{1}$, Henrik Schirmer ${ }^{2}$, Elizabeth Barrett-Connor ${ }^{1}$, Johan Sundfjord ${ }^{3}$ \\ and Rolf Jorde \\ Department of Medicine, University Hospital of North Norway, 9038 Tromsø, Norway, ${ }^{1}$ Department of Family and Preventive Medicine, School of \\ Medicine, University of California, San Diego, La Jolla, CA, USA, ${ }^{2}$ Institute of Community Medicine, University of Tromsø, 9037 Tromsø, Norway and \\ ${ }^{3}$ Department of Clinical Chemistry, University Hospital of North Norway, 9038 Tromsø, Norway \\ (Correspondence should be addressed to J Svartberg; Email: johan.svartberg@unn.no)
}

\begin{abstract}
Objective: To test the hypothesis that lower endogenous testosterone levels are associated with higher blood pressure, left ventricular mass, and left ventricular hypertrophy.

Design: Population-based cross-sectional study.

Methods: Sex hormone levels, measured by immunoassay, anthropometric measurements and resting blood pressure were studied in 1548 men aged 25-84 years; echocardiography was completed in 1264 of these men. Partial correlations and multiple regressions were used to estimate the associations between sex hormones, blood pressure and left ventricular mass by height. Analyses of variance and covariance were used to compare men with categorical hypertension and left ventricular hypertrophy.

Results: In age-adjusted partial correlations, total testosterone and sex hormone-binding globulin (SHBG) were each inversely associated with systolic blood pressure (SBP) $(P<0.001)$. Men with categorical hypertension ( $\mathrm{SBP} \geq 140$ or diastolic blood pressure $(\mathrm{DBP}) \geq 90 \mathrm{mmHg}$ ) had lower levels of total and free testosterone and SHBG before $(P<0.001, P=0.011$ and $P<0.001$, respectively $)$ and after $(P<0.001, P=0.035$ and $P=0.002$, respectively) adjusting for body mass index (BMI). Total testosterone and SHBG were each inversely associated with left ventricular mass $(P<0.001)$, and men with left ventricular hypertrophy had significantly lower levels of total testosterone $(P=0.042)$ and SHBG $(P=0.006)$; these associations were no longer significant after adjusting for BMI

Conclusion: The results of the present study are consistent with the hypothesis that lower levels of testosterone in men are associated with higher blood pressure, left ventricular mass, and left ventricular hypertrophy. The reduced associations after adjusting for BMI suggest that the association of low testosterone levels with blood pressure and left ventricular mass is mediated by obesity.
\end{abstract}

European Journal of Endocrinology 150 65-71

\section{Introduction}

Both systolic and diastolic hypertension are established risk factors for coronary heart disease (CHD). In men, blood pressure increases with age while testosterone, especially free testosterone decreases. Lower endogenous testosterone levels were reported with increasing systolic (SBP) and diastolic blood pressure (DBP) in one case-control study (1), and low levels of testosterone have also been described in hypertensive men $(2-4)$. In cross-sectional studies an inverse relationship between endogenous testosterone and blood pressure has been reported by some (5) but not all $(6-8)$ investigators. Left ventricular hypertrophy is associated with both hypertension and increased cardiovascular morbidity and mortality (9), and it has been suggested that testosterone could be influential in modulating left ventricular mass (10). Little is known, however, about the relationship between endogenous testosterone, left ventricular mass and left ventricular hypertrophy in men.

In the fourth survey of the Tromsø Study, a population-based multipurpose study, which took place in 1994 to 1995 , serum testosterone, blood pressure and body size were measured in 1605 men aged 25 years and older, and echocardiography was performed in 1316 of these men. We used this large database to investigate the possible relationships between endogenous testosterone levels and blood pressure, left ventricular mass and left ventricular hypertrophy. 


\section{Materials and methods}

\section{Study population}

All inhabitants aged $\geq 25$ years living in the municipality of Tromsø were invited to participate in the fourth survey of the Tromsø Study. This fourth survey consisted of two screening visits 4 to 12 weeks apart, and 27159 individuals attended the first visit. All subjects aged 55 to 74 years, random $5 \%$ samples of subjects in other age groups up to age 84 years, as well as 308 men aged 40 to 54 years (selected on the basis of high total cholesterol and/or low high density lipoprotein cholesterol) were invited to a second visit for more extensive examinations. A total of 6891 subjects (3393 men) attended the second visit, representing $79 \%$ of the eligible population (11). Serum samples were drawn for future analysis of sex hormones in a random sample of 1605 men, and echocardiography was performed in 1316 of them. Of the 1605 men who had samples drawn for sex hormone analyses, 1565 men had sufficient serum for all hormone assays. Eight of these men whose total testosterone levels were below the assay detection level, seven men whose sex hormone-binding globulin (SHBG) levels were above the assay reference range and two men using androgen therapy were excluded, leaving 1548 men for the blood pressure analyses and 1264 men for the left ventricular mass and left ventricular hypertrophy analyses.

\section{Questionnaires}

All participants completed two self-administered questionnaires, checked by trained nurses, including information about smoking habits, physical activity, alcohol consumption and medical history. From this questionnaire a physical activity score was computed adding together the hours of easy and vigorous physical activity, with the hours of vigorous activity receiving double weight. The alcohol intake of beer, wine and hard liquor consumed during an average 2-week period was also scored, assuming an equal amount of alcohol in one glass of each type.

\section{Measurements}

Height and weight were measured in subjects wearing light clothing without shoes. Body mass index (BMI) was calculated as weight in kilograms divided by the square of the height in meters $\left(\mathrm{kg} / \mathrm{m}^{2}\right)$. Blood pressure was measured with an automatic device (Dinamap Vital Signs Monitor 1846, Critikon Inc., USA), after subjects were seated for $2 \mathrm{~min}$. Three recordings were made at 2-min intervals, and the mean of the last two were used in this report. Echocardiography was performed by medical doctors, using a VingMed CFM 750 (VingMed Sound A/S, Horten, Norway). Subjects were examined in a supine, left lateral position with a combined $3.25 \mathrm{MHz}$ mechanical and a $2.5 \mathrm{MHz}$ Doppler probe. The echocardiographic examinations were performed using the standard apical and parasternal long- and short-axis views. Left ventricular diastolic dimensions from one heart cycle were measured online from standard two-dimensional guided M-mode registrations according to the recommendations of the American Society of Echocardiography (12), using EchoPAC software (VingMed Sound). Registrations were regarded as adequate for measurement if both margins of the septum and the posterior wall were visible throughout one heart cycle. Left ventricular mass was calculated using the correction formula of Devereux et al. (13). Left ventricular mass was indexed for height to control for the increase in left ventricular mass with increasing height, without masking the increase in left ventricular mass with increasing BMI (14). Left ventricular hypertrophy was defined by sexspecific 97.5 percentiles of left ventricular mass by height in a healthy reference group, aged 25-76 years, from the total echo sample (15). The cut-off normal value for men was $<145.5 \mathrm{~g} / \mathrm{m}$.

The presence of valvular heart disease was evaluated by two dimensional colour Doppler for mitral insufficiency, colour M-mode for aortic insufficiency and pulsed wave Doppler for mitral and aortic stenosis.

Blood was drawn by venipuncture from non-fasting men between 0800 and $1600 \mathrm{~h}$. Serum samples were stored at $-70^{\circ} \mathrm{C}$, until they were first thawed for analyses of sex hormones in 2001. Determination of total testosterone and SHBG was performed on Immulite 2000 (Diagnostic Product Corp., Los Angeles, CA, USA). Free testosterone values were calculated from total testosterone and SHBG using a fixed albumin of $43.0 \mathrm{~g} / \mathrm{l}$ according to the method of Vermeulen et al. (16). Coefficients of variation were based on assays of pooled human sera at two hormone levels run in parallel each day. The intra- and interassay coefficients of variation for total testosterone were $3.5 \%$ and $5 \%$ respectively at a concentration above $1 \mathrm{nmol} / \mathrm{l}$ and $12 \%$ and $20 \%$ respectively in the range 0.1 (limit of detection) $-1.0 \mathrm{nmol} / \mathrm{l}$. For SHBG the intra- and interassay coefficients of variation were $3.5 \%$ and $6 \%$ respectively and the limit of detection was $1.0 \mathrm{nmol} / \mathrm{l}$.

\section{Statistical analyses}

Partial correlations were used to determine the crosssectional associations between blood pressure, left ventricular mass indexed by height, and individual hormone levels adjusted for age, BMI or waist circumference and life-style factors. Multiple regression analyses, with blood pressure or left ventricular mass indexed by height as the dependent variable were performed to evaluate the independent contribution of testosterone, age, BMI or waist circumference, and life-style factors. Baseline distribution of testosterone 
and SHBG was examined by categorically defined hypertension $(\mathrm{SBP} \geq 140 \mathrm{mmHg}$ and/or $\mathrm{DBP} \geq 90$ $\mathrm{mmHg}$ including individuals on medication for hypertension) or left ventricular hypertrophy $(\geq 145.5 \mathrm{~g} / \mathrm{m})$ in age-specific categories. Analysis of covariance was used to calculate adjusted means of testosterone and SHBG by blood pressure and left ventricular hypertrophy status. The covariates age and BMI were included as continuous variables in the model. All statistical tests were two-tailed with statistical significance defined as $P<0.05$. The data were analyzed using the SPSS statistical package for Windows version 10.1 (SPSS Inc., Chicago, IL, USA).

\section{Ethics}

The Tromsø Regional Ethics Committee approved the study, and all participants gave written informed consent.

\section{Results}

The characteristics of the 1548 men are summarized in Table 1. Approximately $50 \%$ had hypertension of whom $13.4 \%$ were using medication for hypertension. A history of CHD was reported by $15.2 \%$, stroke by $2.6 \%$ and diabetes by $3.2 \%$.

In age-adjusted partial correlations total testosterone and SHBG were inversely and significantly (all $P<0.001)$ associated with DBP $(r=-0.10$ and $r=-0.13$ respectively $)$ and $\operatorname{SBP}(r=-0.12$ and

Table 1 Characteristics of the 1548 Troms $\varnothing$ men (mean \pm S.D. or percent).

\begin{tabular}{|c|c|}
\hline $\begin{array}{l}\text { Age (years) } \\
\text { (Range) }\end{array}$ & $\begin{array}{c}60.3 \pm 10.1 \\
(25-84)\end{array}$ \\
\hline \multicolumn{2}{|l|}{ Anthropometric characteristics } \\
\hline Height $(\mathrm{cm})$ & $175.2 \pm 6.9$ \\
\hline Weight $(\mathrm{kg})$ & $80.3 \pm 12.1$ \\
\hline Body mass index $\left(\mathrm{kg} / \mathrm{m}^{2}\right)$ & $26.1 \pm 3.4$ \\
\hline Waist circumference (cm) & $95.4 \pm 9.2$ \\
\hline \multicolumn{2}{|l|}{ Hormone levels } \\
\hline Total testosterone $(\mathrm{nmol} / \mathrm{l})$ & $13.2 \pm 5.1$ \\
\hline Free testosterone (pmol/l) & $205 \pm 75$ \\
\hline Sex hormone-binding globulin (nmol/l) & $51.6 \pm 22.3$ \\
\hline Systolic blood pressure $(\mathrm{mmHg})$ & $140.8 \pm 19.8$ \\
\hline Diastolic blood pressure (mmHg) & $81.7 \pm 11.5$ \\
\hline \multicolumn{2}{|l|}{ Echocardiography* } \\
\hline Left ventricular mass $(\mathrm{g})$ & $201.4 \pm 60.9$ \\
\hline Left ventricular mass by height $(\mathrm{g} / \mathrm{m})$ & $115.0 \pm 34.8$ \\
\hline $\begin{array}{l}\text { Smoking - cigarettes/day: none/1-10/ } \\
11 \text { or more (\%) }\end{array}$ & $67 / 26 / 7$ \\
\hline $\begin{array}{l}\text { Alcohol - units/two weeks: none/1-14/ } \\
15 \text { or more (\%) }\end{array}$ & $35 / 58 / 7$ \\
\hline Physical activity score: $0-3 / 4-6 / 7-9(\%)$ & $58 / 23 / 19$ \\
\hline
\end{tabular}

$r=-0.13$ respectively). There was a weak inverse association between free testosterone and SBP $(r=-0.05 ; P=0.038)$. Both DBP and SBP were positively associated with BMI $(r=0.24 ; P<0.001$ and $r=0.18 ; P<0.001$ respectively) and with alcohol consumption $(r=0.07 ; P=0.010$ and $r=0.08$; $P=0.003$ respectively). SBP was also inversely associated with the number of cigarettes smoked $(r=-0.06$; $P=0.019)$.

In multiple regression analyses, total testosterone, age, BMI or waist circumference, and alcohol consumption were significantly and independently associated with systolic blood pressure; age, BMI or waist circumference and alcohol consumption were associated with diastolic blood pressure (Table 2). Excluding men on treatment for hypertension did not materially change the results.

In the 1264 men with valid data on left ventricular mass by height, there was an inverse age-adjusted partial correlation between left ventricular mass by height and total testosterone $(r=-0.10 ; P<0.001)$ and SHBG $(r=-0.14 ; P<0.001)$. Left ventricular mass by height was positively associated to both systolic $(r=0.26 ; \quad P<0.001)$ and diastolic $(r=0.24$; $P<0.001)$ blood pressure, and with BMI $(r=0.39$; $P<0.001)$. Left ventricular mass by height was not associated with lifestyle factors. In multiple regression analyses, age, systolic blood pressure, valvular heart disease and BMI or waist circumference were each independently associated with left ventricular mass by height. Total testosterone and SHBG were independently associated with left ventricular mass by height before but not after BMI or waist circumference was added to the model (Table 3). Excluding men with CHD did not materially change these results.

Table 4 shows mean hormone levels by categorical hypertension including men with hypertensive medication. In age-adjusted analyses, men with hypertension had lower levels of total testosterone (12.4 vs $14.0 \mathrm{nmol} / \mathrm{l} ; \quad P<0.001)$, free testosterone (201 vs $210 \mathrm{pmol} / \mathrm{l} ; P<0.011$ ), and SHBG (48.4 vs $54.7 \mathrm{nmol} / \mathrm{l}$; $P<0.001)$. Adjusting for BMI weakened but did not change these associations. In addition, these differences were consistent within age-specific groups. In age-adjusted analysis, men with left ventricular hypertrophy had lower levels of total testosterone (12.6 vs $13.5 \mathrm{nmol} / \mathrm{l} ; P<0.042$ ) and SHBG (47.1 vs $51.6 \mathrm{nmol} / \mathrm{l} ; P<0.006)$. However, these associations were no longer present after adjusting for BMI.

Additional analyses adjusting for time of day and season of venipuncture did not materially change these associations.

\section{Discussion}

Views on the relationship between testosterone and blood pressure are conflicting. In cross-sectional studies 
Table 2 Multiple regression analyses with systolic and diastolic blood pressure as dependent variables.

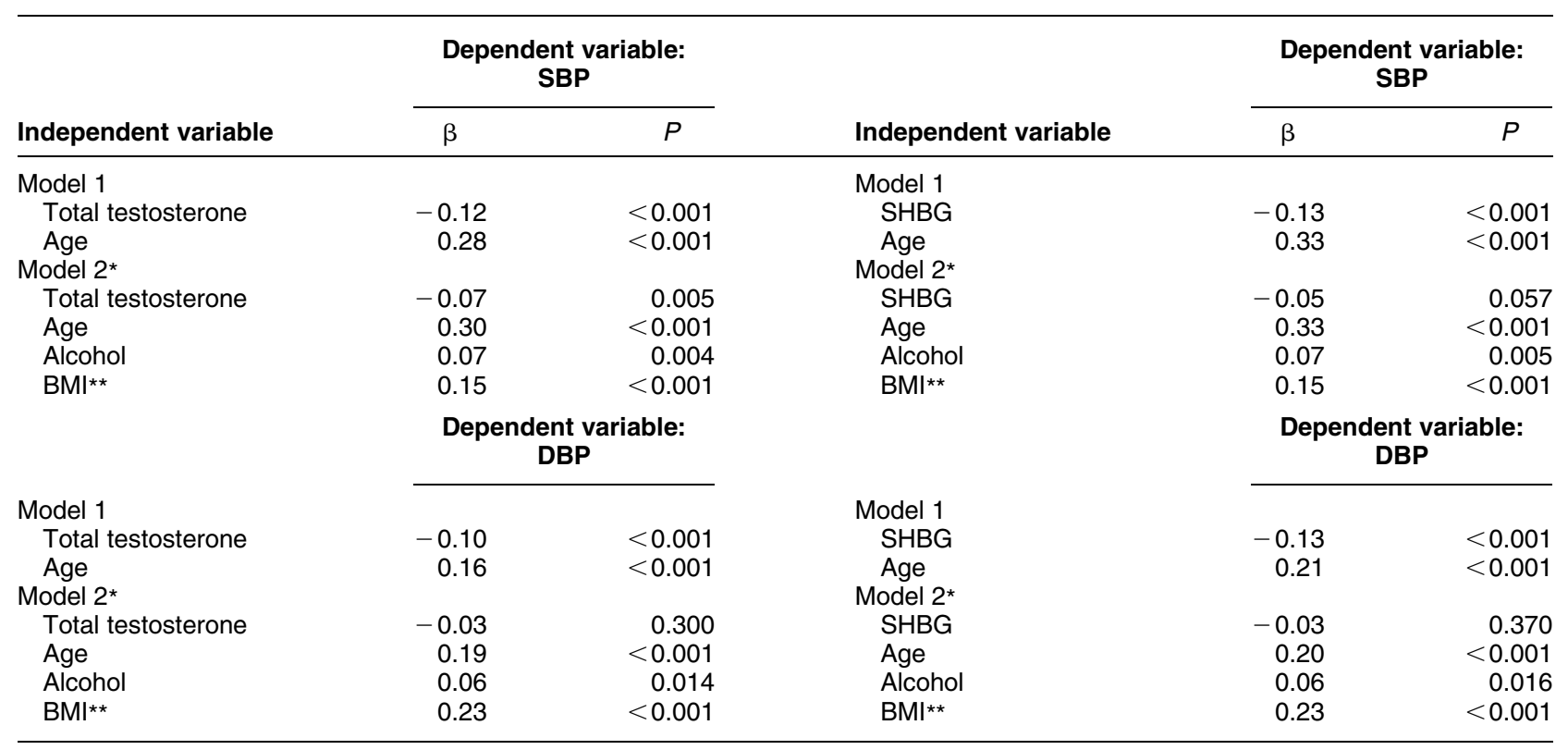

*Smoking and physical activity were not significant and were excluded. ${ }^{*}$ Using waist circumference in the model instead of BMI gave the same result.

an inverse association with both systolic and diastolic blood pressure has been reported by some investigators (5), in agreement with our finding, but not by all (6-8). In a longitudinal study of 66 men over 13 years (former participants of the Multiple Risk Factor Intervention Trial, MRFIT) no association was found between testosterone and blood pressure (17).
We found lower levels of total testosterone in hypertensive men, consistent with four previous reports $(2-5)$, while two other investigators reported no difference $(18,19)$. It is, however, important to notice that no study has reported a positive association between testosterone and blood pressure or found higher levels of testosterone in hypertensive men.

Table 3 Multiple regression analyses with left ventricular mass as dependent variable.

\begin{tabular}{|c|c|c|c|c|c|}
\hline \multirow[b]{2}{*}{ Independent variable } & \multicolumn{2}{|c|}{$\begin{array}{c}\text { Dependent variable: } \\
\text { left ventricular mass } \\
\text { by height }\end{array}$} & \multirow[b]{2}{*}{ Independent variable } & \multicolumn{2}{|c|}{$\begin{array}{c}\text { Dependent variable: } \\
\text { left ventricular mass } \\
\text { by height }\end{array}$} \\
\hline & $\beta$ & $P$ & & $\beta$ & $P$ \\
\hline Model 1 & & & Model 1 & & \\
\hline Total testosterone & -0.10 & $<0.001$ & SHBG & -0.15 & $<0.001$ \\
\hline Age & 0.16 & $<0.001$ & Age & 0.22 & $<0.001$ \\
\hline Model 2 & & & Model 2 & & \\
\hline Total testosterone & -0.08 & 0.005 & SHBG & -0.12 & $<0.001$ \\
\hline Age & 0.08 & 0.002 & Age & 0.13 & $<0.001$ \\
\hline Systolic blood pressure & 0.19 & $<0.001$ & Systolic blood pressure & 0.19 & $<0.001$ \\
\hline Diastolic blood pressure & 0.09 & 0.019 & Diastolic blood pressure & 0.09 & 0.028 \\
\hline Model 3 & & & Model 3 & & \\
\hline Total testosterone & -0.08 & 0.002 & SHBG & -0.12 & $<0.001$ \\
\hline Age & 0.06 & 0.027 & Age & 0.11 & $<0.001$ \\
\hline Systolic blood pressure & 0.18 & $<0.001$ & Systolic blood pressure & 0.18 & $<0.001$ \\
\hline Diastolic blood pressure & 0.11 & 0.004 & Diastolic blood pressure & 0.11 & 0.006 \\
\hline Valvular disease & 0.20 & $<0.001$ & Valvular disease & 0.20 & $<0.001$ \\
\hline Model 4 & & & Model 4 & & \\
\hline Total testosterone & 0.02 & 0.431 & SHBG & 0.02 & 0.393 \\
\hline Age & 0.10 & $<0.001$ & Age & 0.09 & 0.001 \\
\hline Systolic blood pressure & 0.18 & $<0.001$ & Systolic blood pressure & 0.20 & $<0.001$ \\
\hline Valvular disease & 0.21 & $<0.001$ & Valvular disease & 0.21 & $<0.001$ \\
\hline $\mathrm{BMI}^{*}$ & 0.36 & $<0.001$ & $\mathrm{BMI}^{*}$ & 0.37 & $<0.001$ \\
\hline
\end{tabular}

*Using waist circumference in the model instead of BMI gave the same result. 
Table 4 Mean and S.D. total and free testosterone and SHBG levels by categorical hypertension and by left ventricular hypertrophy (LVH).

\begin{tabular}{|c|c|c|c|c|c|c|c|c|c|c|c|c|c|c|}
\hline \multirow[b]{2}{*}{ Age (years) } & \multicolumn{3}{|c|}{$\begin{array}{c}\text { No hypertension } \\
(\mathrm{SBP}<140 \text { and } \\
\mathrm{DBP}<90)\end{array}$} & \multicolumn{3}{|c|}{$\begin{array}{c}\text { Hypertension } \\
(\mathrm{SBP} \geq 140 \\
\text { and/or } \mathrm{DBP} \geq 90)\end{array}$} & \multirow[b]{2}{*}{$\boldsymbol{P}$} & \multicolumn{3}{|c|}{$\begin{array}{c}\text { No LVH } \\
(<145.5 \mathrm{~g} / \mathrm{m})\end{array}$} & \multicolumn{3}{|c|}{$\begin{array}{c}\text { LVH } \\
(\geq 145.5 \mathrm{~g} / \mathrm{m})\end{array}$} & \multirow[b]{2}{*}{$\boldsymbol{P}$} \\
\hline & $n$ & Mean & S.D. & $n$ & Mean & S.D. & & $n$ & Mean & S.D. & $n$ & Mean & S.D. & \\
\hline \multicolumn{15}{|l|}{ Total testosterone (nmol/l) } \\
\hline $25-39$ & 59 & 15.3 & 6.0 & 15 & 13.3 & 4.4 & & 72 & 15.0 & 5.8 & 2 & 12.0 & 1.5 & \\
\hline $40-49$ & 87 & 14.2 & 5.0 & 37 & 12.6 & 5.0 & & 103 & 14.1 & 5.1 & 8 & 10.3 & 2.3 & \\
\hline $50-59$ & 271 & 14.0 & 5.3 & 182 & 12.1 & 4.6 & & 353 & 13.4 & 5.3 & 55 & 12.8 & 4.1 & \\
\hline $60-69$ & 285 & 13.8 & 4.8 & 320 & 12.4 & 5.1 & & 381 & 13.4 & 5.1 & 77 & 12.6 & 5.4 & \\
\hline $70-84$ & 81 & 13.4 & 5.4 & 211 & 12.3 & 5.1 & & 167 & 12.8 & 5.4 & 46 & 12.5 & 4.7 & \\
\hline All 25-84 (age-adjusted) & 783 & 14.0 & 5.2 & 765 & 12.4 & 4.9 & $<0.001$ & 1076 & 13.5 & 5.3 & 188 & 12.6 & 4.7 & 0.042 \\
\hline All (age- and BMI-adjusted) & & 13.7 & & & 12.7 & & $<0.001$ & & 13.3 & & & 13.6 & & 0.453 \\
\hline \multicolumn{15}{|l|}{ Free testosterone $(\mathrm{pmol} / \mathrm{l})$} \\
\hline $25-39$ & & 307 & 109 & & 265 & 67 & & & 300 & 104 & & 259 & 56 & \\
\hline $40-49$ & & 254 & 77 & & 252 & 84 & & & 255 & 79 & & 232 & 71 & \\
\hline $50-59$ & & 226 & 81 & & 206 & 62 & & & 218 & 76 & & 225 & 66 & \\
\hline $60-69$ & & 196 & 58 & & 188 & 62 & & & 195 & 62 & & 190 & 66 & \\
\hline $70-84$ & & 168 & 63 & & 171 & 59 & & & 172 & 57 & & 169 & 63 & \\
\hline All 25-84 (age-adjusted) & & 210 & 82 & & 201 & 66 & 0.011 & & 210 & 78 & & 209 & 769 & 0.794 \\
\hline All (age- and BMI-adjusted) & & 209 & & & 202 & & 0.035 & & 209 & & & 212 & & 0.625 \\
\hline \multicolumn{15}{|l|}{ SHBG $(\mathrm{nmol} / \mathrm{l})$} \\
\hline $25-39$ & & 36.5 & 15.3 & & 34.1 & 14.9 & & & 36.2 & 15.4 & & 30.0 & 4.2 & \\
\hline $40-49$ & & 42.0 & 16.5 & & 33.9 & 15.4 & & & 40.7 & 16.8 & & 27.6 & 12.4 & \\
\hline $50-59$ & & 49.2 & 19.2 & & 43.8 & 19.1 & & & 47.7 & 19.5 & & 42.3 & 16.3 & \\
\hline $60-69$ & & 57.3 & 20.4 & & 52.1 & 23.1 & & & 55.5 & 22.5 & & 51.1 & 21.1 & \\
\hline $70-84$ & & 69.2 & 28.2 & & 58.6 & 22.8 & & & 61.5 & 24.4 & & 60.9 & 17.1 & \\
\hline All 25-84 (age-adjusted) & & 54.7 & 21.9 & & 48.4 & 22.7 & $<0.001$ & & 51.6 & 22.0 & & 47.1 & 20.2 & 0.006 \\
\hline All (age- and BMI-adjusted) & & 53.1 & & & 50.0 & & 0.002 & & 50.8 & & & 52.2 & & 0.357 \\
\hline
\end{tabular}

To our knowledge only one study has examined the relationship between testosterone levels and left ventricular mass and found no association in unadjusted or adjusted analyses (20). The prevalence of left ventricular hypertrophy was not reported. In contrast, we found an inverse association between total testosterone and left ventricular mass by height and lower testosterone levels in men with left ventricular hypertrophy. These associations were independent of age but were no longer present after adjusting for BMI or waist circumference, suggesting that the link between total testosterone and left ventricular mass by height is mediated by body fat or body fat distribution. Others have reported that low levels of total testosterone are associated with increasing obesity $(1,21,22)$ and predict central obesity (23). Further, administration of low-dose testosterone to hypogonadal men increased fat-free mass and reduced total and central fat mass (24). If low levels of total testosterone increase overall obesity, especially central obesity, adjusting for BMI, waist circumference or waist-hip ratio to assess cardiovascular risk factors could be considered overadjusting. BMI may emerge as the strongest covariate because it is more precisely measured than testosterone.

In this study, we found lower levels of free testosterone in men with hypertension, but not in men with left ventricular hypertrophy. Free testosterone represents a small part $(1-2 \%$; in our study $1.6 \%)$ of total testosterone and the level is influenced both by total testosterone and by SHBG levels (18). If total testosterone and SHBG decrease in parallel, free testosterone might be unchanged. We believe this could be a plausible explanation as to why free testosterone was not lower in men with left ventricular hypertrophy.

There could be several possible explanations for the association between testosterone, blood pressure and left ventricular mass by height. A genetic link between hypertension and serum testosterone levels has been suggested by a study showing that men with a family history of hypertension have lower levels of testosterone (25). Mice lacking the gene encoding the natriuretic peptide receptor A (Npr1) are characterized by both high blood pressure and low circulating levels of testosterone (26). Testosterone may exert antihypertensive effects on the vasculature as testosterone induces endothelium-independent relaxation of isolated rabbit and rat aorta $(27,28)$, and testosterone has also been shown to have a beneficial effect on myocardial ischemia (29) and coronary blood flow in men with CHD (30). These observations suggest a direct role for testosterone in modulating vessel resistance and arterial blood flow. In a recent study of patients with prostate cancer, treatment-induced hypogonadism was associated with increased central arterial pressure suggesting arterial stiffening (31). Arterial stiffening leads to changes in arterial pressure waveform, and ultimately increases central systolic blood pressure (32). Central pressure is the major determinant of left ventricular 
afterload and the subsequent development of left ventricular hypertrophy $(32,33)$, and is an independent cardiovascular risk factor (9). However, the precise mechanism underlying the relationship between low testosterone levels, hypertension, and left ventricular mass by height is still elusive.

Limitations of this study should be considered. Hormone levels were based on a single serum sample, drawn between 0800 and $1600 \mathrm{~h}$. Preferably, samples should have been drawn in the morning because of the diurnal variation of total and free testosterone; we observed the expected higher levels of both total and free testosterone in the morning, but adjusting for time and season of venipuncture did not change these associations or lack of associations. Blood samples were kept frozen for approximately 6.5 years at $-70^{\circ} \mathrm{C}$ and hormone levels were measured when samples were thawed for the first time. Levels of steroid hormones have been shown to be relatively stable in frozen serum for up to 10 years $(34,35)$. SHBG has documented stability only in short-term frozen storage (35); reduced levels have been reported after longer storage (36). However, this would not be expected to alter the ordinal associations for the observed levels. We did not measure free testosterone but used calculated values. However, two independent investigators have recently reported that this calculation using fixed albumin is accurate and reliable $(16,37)$.

In summary, total testosterone was inversely associated with systolic blood pressure, and men with hypertension had lower levels of total and free testosterone and SHBG. Inverse associations were also seen between total testosterone and SHBG with left ventricular mass by height, and men with left ventricular hypertrophy had lower levels of total testosterone and SHBG. Results of the present study are consistent with the hypothesis that lower levels of testosterone in men are associated with CHD risk factors. We suggest that low testosterone-mediated obesity is a plausible mechanism for this association.

\section{Acknowledgements}

Local funds from the University Hospital of North Norway and a grant from the Caroline Musæus Aarsvolds Fund supported this work. The excellent technical assistance of Astrid Lindvall and Inger Myrnes, Department of Clinical Chemistry, with the sex hormone analyses is greatly appreciated.

\section{References}

1 Simon D, Charles M-A, Nahoul K, Orssaud G, Kremski J, Hully V et al. Association between plasma testosterone and cardiovascular risk factors in healthy adult men: The Telecom Study. Journal of Clinical Endocrinology and Metabolism 199782 682-685.
2 Hughes GS, Mathur RS \& Margolius HS. Sex steroid hormones are altered in essential hypertension. Journal of Hypertension 19897 $181-187$.

3 Phillips GB, Jing TY, Resnick M, Barbagallo M, Laragh JH \& Sealey JE. Sex hormones and hemostatic risk factors for coronary heart disease in men with hypertension. Journal of Hypertension 1993 $11699-702$.

4 Jaffe A, Chen Y, Kisch ES, Fischel B, Alon M \& Stern N. Erectile dysfunction in hypertensive subjects. Assessment of potential determinants. Hypertension $1996 \mathbf{2 8}$ 859-862.

5 Khaw KT \& Barrett-Connor E. Blood pressure and endogenous testosterone in men: an inverse relationship. Journal of Hypertension $19886329-332$.

6 Lindholm J, Winkel P, Brodthagen U \& Gyntelberg F. Coronary risk factors and plasma sex hormones. American Journal of Medicine $198273648-651$.

7 Bonithon-Kopp C, Scarabin PY, Bara L, Castanier M, Jacqueson A \& Roger M. Relationship between sex hormones and haemostatic factors in healthy middle-aged men. Atherosclerosis $1988 \mathbf{7 1}$ $71-76$.

8 Dai WS, Gutai JP, Kuller LH, Laporte RE, Falvo-Gerard L \& Caggiula A. Relation between plasma high-density lipoprotein cholesterol and sex hormone concentration in men. American Journal of Cardiology 198453 1259-1263.

9 Levy D, Garrison RJ, Savage DD, Kannel WB \& Castelli WP. Prognostic implications of echocardiographically determined left ventricular mass in the Framingham heart study. New England Journal of Medicine 1990322 1561-1566.

10 Hayward CS, Webb CM \& Collins P. Effect of sex hormones on cardiac mass. Lancet 2001357 1354-1356.

11 Mathiesen EB, Bønaa KH \& Joakimsen O. Low levels of high-density lipoprotein cholesterol are associated with echolucent carotid artery plaques: The Tromsø Study. Stroke 200132 1960-1965.

12 O'Rourke RA, Hanrath P, Henry WN, Hugenholtz PG, Pisa Z, Roelandt J et al. Report of the Joint International Society and Federation of Cardiology/World Health Organization Task Force on recommendations for standardization of measurements from m-mode echocardiograms. Circulation $198469854 \mathrm{~A}-857 \mathrm{~A}$.

13 Devereux RB, Alonso DR, Lutas EM, Gottlieb GJ, Campo E, Sachs I et al. Echocardiographic assessment of left ventricular hypertrophy: comparison to necropsy findings. American Journal of Cardiology $1986 \mathbf{5 7} 450-458$.

14 Levy D, Savage DD, Garrison RJ, Anderson KM, Kannel WB \& Castelli WP. Echocardiographic criteria for left ventricular hypertrophy: the Framingham Heart Study. American Journal of Cardiology 198759 956-960.

15 Schirmer H, Lunde P \& Rasmussen K. Prevalence of left ventricular hypertrophy in a general population. The Tromsø Study. European Heart Journal 199920 429-438.

16 Vermeulen A, Verdonck L \& Kaufman JM. A critical evaluation of simple methods for the estimation of free testosterone in serum. Journal of Clinical Endocrinology and Metabolism $1999 \mathbf{8 4}$ 3666-3672.

17 Zmuda JM, Cauley JA, Kriska A, Glynn NW, Gutai JP \& Kuller LH. Longitudinal relation between endogenous testosterone and cardiovascular disease risk factors in middle-aged men. A 13-year follow-up of former Multiple Risk Factor Intervention Trial participants. American Journal of Epidemiology 1997146 609-617.

18 Dai WS, Kuller LH, LaPorte RE, Gutai JP, Falvo-Gerard L \& Caggiula A. The epidemiology of plasma testosterone levels in middle-aged men. American Journal of Epidemiology $1981 \mathbf{1 1 4}$ $804-816$.

19 Labropoulos B, Velonakis E, Oekonomados P, Laskans J \& Katsimades D. Serum sex hormones in patients with coronary heart disease and their relationship to known factors causing atherosclerosis. Cardiology 198269 98-103.

20 Gyllenborg J, Rasmussen SL, Borch-Johnsen K, Heitmann BL, Skakkebæk NE \& Juul A. Cardiovascular risk factors in men: the role of gonadal steroids and sex hormone-binding globulin. Metabolism $200150882-888$. 
21 Zumoff B, Strain GW, Miller LK, Rosner W, Senie R, Seres DS et al. Plasma free and non-sex-hormone-binding-globulin-bound testosterone are decreased in obese men in proportion to their degree of obesity. Journal of Clinical Endocrinology and Metabolism 199071 929-931.

22 Haffner SM, Karhapaa P, Mykkanen L \& Laakso M. Insulin resistance, body fat distribution, and sex hormones in men. Diabetes $199443212-219$.

23 Khaw KT \& Barrett-Connor E. Lower endogenous androgens predict central adiposity in men. Annals of Epidemiology 19922 675-682.

24 Vermeulen A, Goemaere S \& Kaufman JM. Testosterone, body composition and aging. Journal of Endocrinological Investigations 199922 (Suppl 5) 110-116.

25 Endre T, Mattiasson I, Berglund G \& Hulthén UL. Low testosterone and insulin resistance in hypertension-prone men. Journal of Human Hypertension $199610755-761$.

26 Pandey KN, Oliver PM, Maeda N \& Smithies O. Hypertension associated with decreased testosterone levels in natriuretic peptide receptor-A gene-knockout and gene-duplicated mutant mouse models. Endocrinology $19991405112-5119$.

27 Yue P, Chatterjee K, Beale C, Poole-Wilson PA \& Collin P. Testosterone relaxes rabbit coronary arteries and aorta. Circulation $1995911154-1160$.

28 Costarella CE, Stallone JN, Rutecki GW \& Whittier FC. Testosterone causes direct relaxation of rat thoracic aorta. Journal of Pharmacology and Experimental Therapeutics 1996277 34-39.

29 Webb CM, Adamson DL, de Zeigler D \& Collins P. Effect of acute testosterone on myocardial ischemia in men with coronary artery disease. American Journal of Cardiology 199983 437-439.

30 Webb CM, McNeill JG, Hayward CS, de Zeigler D \& Collins P. Effects of testosterone on coronary vasomotor regulation in men with coronary heart disease. Circulation $1999 \mathbf{1 0 0}$ $1690-1696$.

31 Smith JC, Bennett S, Evans LM, Kynaston HG, Parmar M, Mason MD et al. The effects of induced hypogonadism on arterial stiffness, body composition, and metabolic parameters in males with prostate cancer. Journal of Clinical Endocrinology and Metabolism 200186 4261-4267.

32 O'Rourke MF \& Kelly RP. Wave reflection in the systemic circulation and its implications in ventricular function. Journal of Hypertension $199311327-337$.

33 Saba PS, Roman MJ, Pini R, Spitzer M, Ganau A \& Devereux RB. Relation of arterial pressure waveform to left ventricular and carotid anatomy in normotensive subjects. Journal of the American College of Cardiology 199322 1873-1880.

34 Bolelli G, Muti P, Micheli A, Sciajno R, Franceschetti F, Krogh V et al. Validity for epidemiological studies of long-term cryoconservation of steroid and protein hormones in serum and plasma. Cancer, Epidemiology, Biomarkers and Prevention 19954 509-513.

35 Kley HK, Schlaghecke R \& Kruskemper HL. Stability of steroid in plasma over a 10-year period. Journal of Clinical Chemistry and Clinical Biochemistry 198523 875-878.

36 Harman SM, Metter EJ, Tobin JD, Pearson J \& Blackman MR. Longitudinal effects of aging on serum total and free testosterone levels in healthy men. Journal of Clinical Endocrinology and Metabolism 200186 724-731.

37 Morley JE, Patrick P \& Perry HM 3rd. Evaluation of assays available to measure free testosterone. Metabolism $2002 \mathbf{5 1} 554-559$.

Received 8 August 2003

Accepted 14 October 2003 